Article

\title{
Fan (Fiction) Acting on Media and the Politics of Appropriation
}

\author{
Wolfgang Reißmann *, Moritz Stock, Svenja Kaiser, Vanessa Isenberg and Jörg-Uwe Nieland \\ Collaborative Research Center “Media of Cooperation", University of Siegen, 57068 Siegen, Germany; E-Mails: \\ reissmann@sfb1187.uni-siegen.de (W.R.), moritz.stock@uni-siegen.de (M.S.), svenja.kaiser@student.uni-siegen.de (S.K.), \\ vanessa.isenberg@student.uni-siegen.de (V.I.), joerg-uwe.nieland@uni-siegen.de (J.-U.N.)
}

* Corresponding author

Submitted: 10 April 2017 | Accepted: 12 July 2017 | Published: 22 September 2017

\begin{abstract}
Fanfiction is the creative appropriation and transformation of existing popular media texts by fans who take stories, worlds and/or characters as starting points and create their own stories based on them. As a cultural field of practice, fanfiction questions prevalent concepts of individual authorship and proprietary of cultural goods. At the same time, fanfiction itself is challenged. Through processes of mediatization, fanfiction grew and became increasingly visible. Third parties, ranging from the media industry (e.g., film studios) and copyright holders to journalism and academia, are interested in fanfiction and are following its development. We regard fanfiction communities and fan acting as fields for experimentation and as discursive arenas which can help understand what appropriating, writing and publishing in a digital culture and the future of writing might look like. In this paper, we outline important debates on the legitimacy and nature of fanfiction and present preliminary results of current research within Germany.
\end{abstract}

\section{Keywords}

appropriation; collective and distributed authorship; commercialization; copyright; fanfiction; gift culture

\section{Issue}

This article is part of the issue "Acting on Media: Influencing, Shaping and (Re)Configuring the Fabric of Everyday Life", edited by Sigrid Kannengießer and Sebastian Kubitschko (University of Bremen, Germany).

(C) 2017 by the authors; licensee Cogitatio (Lisbon, Portugal). This article is licensed under a Creative Commons Attribution 4.0 International License (CC BY).

\section{Fans, Fanfiction and Acting on Media}

Fanfiction is the creative appropriation and transformation of existing popular media texts by fans who take stories, worlds and/or characters as starting points and create their own stories based on it. As a cultural field of practice, it is supposed to have existed since the $20^{\text {th }}$ century with Jane Austen and Sherlock Holmes societies in the 1920s as well as Star Trek fanzines in the late 1960s (Derecho, 2006, p. 62). Looking to regional differences, e.g. in Germany, also transformative writings based on Karl May novels in the late $19^{\text {th }}$ century can be seen as a starting point (Cuntz-Leng \& Meintzinger, 2015). And when arguing that fanfiction may be as old as myth stories several millennia ago (one of three argumentations outlined by Derecho, 2006, p. 62; see also Jamison, 2013, pp. 26ff.), we are in the middle of the debate; this article deals with the politics of appropriation.
The paper applies the concept of "acting on media" to fanfiction and contested understandings and ways of derivative respectively transformative writing, publishing and work-related interacting. Historically, fanzines and devices such as mimeographs and later photocopiers were the most important means for publishing and exchange. Today, digital platforms and repositories such as Fanfiction.net, Archive of Our Own (Ao3), Animexx, and services such as personalized Tumblr blogs and social media (social network sites, instant messengers) are crucial for establishing and maintaining fanfiction communities. Much of what is discussed today and partly seen as digital phenomena, is anything but new. For instance, fan actors used fanzines not only to circulate fan written stories in the analog era but also to develop complex, multi-authored stories (Lichtenberg, as cited in Jamison, 2013, pp. 91ff.). However, in former times, the activities of writing and publishing occurred in relatively separate 
ecological provinces. What changed through processes of media convergence and mediatization is the emergence of low-threshold access and opportunities to (partial) public articulation on the one side, and increased visibility of fan activities on the other side. Contradictions intensify when ever-present fans' will "to meaningfully quote from their culture" (Jenkins, 2009, online) and practices of sharing, publishing and spreading contents come together with observation and evaluation by third parties such as the media industry, copyright holders, and academics.

If we understand acting on media (Kannengießer \& Kubitschko, 2017) as a focus on how special interest groups or social movements not only use media and infrastructure but also shape media ecologies and/or take an active part in the molding of everyday life practicesto a large extent, fanfiction is acting on media. First, in a literal sense, fan (fiction) acting on media is infrastructuring communities and publics. Authors, fan activists, bloggers, and platform runners invest time, effort and work to set up and maintain fanfiction communities by creating the material architecture, by producing texts and other contents, by sorting and archiving stories and other more. Secondly, fan (fiction) acting on media is acting on the political-juridical conditions which frame derivative working and publishing of derivative material. As a cultural field of practice, fanfiction is challenging insofar as it questions prevalent concepts of authorship and proprietary of cultural goods.

With regard to the political character of fan (fiction) acting on media, we distinguish between an individual and a collective view, and between explicit and implicit political groundings of acting. From the point of view of individual fanfiction authors or platform staff members, they can, but do not necessarily regard themselves as part of a bigger project or movement, whereas others do. Changing the perspective, collectively, intended or not, every contribution to fanfiction is part of practices and cultures larger than the individual. People may act very consciously as fans, intending to preserve, celebrate, improve or change existing media culture. By contrast, others may just love their fandom, just act, and not think about (fan) politics at all. We do well not to use notions such as "collective" and "implicit" as blackboxes for totalitarian academic fantasy on the political character of everyday action. Yet, with de Certeau (1984, pp. xix, 34-39) we regard fanfiction practices as tacti$c a l$ in the sense that authors act on others' territories. This is neither to say that we like to repeat and affirm prevalent social and cultural orders pushing fanfiction into a sphere without its own space, nor do we deny that fans create their own semiotic and (quasi-)material spaces, or occupy official and production-based spaces. ${ }^{1}$ On the contrary, fanfiction infrastructures often emerge independently from cultural industries' big players and their media. Nevertheless, fanfiction is still culturally subordinated and so, fanfiction as collective action opposes dominant patterns and it questions "owned spaces".

Fanfiction communities and their acting on media are fields for experimentation and discursive arenas which can help understand how appropriating, writing, publishing and infrastructuring communicative spaces and publics work in a digital culture. At the same time, fanfiction is seismographic for existing contradictories and the "messy" blurring and entanglement of justification orders and doings. We like to show both and discuss contested issues theoretical as well as on the basis of own data.

\section{Fan Studies and Empirical Legal Studies}

In the following three chapters, we introduce ongoing debates regarding fanfiction and present preliminary results from a research project, currently being conducted within the Collaborative Research Center "Media of Cooperation", at the University of Siegen, Germany.

Focusing on derivative writing and publishing, the project is a joint venture of media sociology and copyright law scholarship. It contributes to fan studies, insofar as it seeks to map different ways of how fanfiction actors cooperate, how fan texts develop, how fan works are published and (re-)negotiated, and how mediating infrastructures keep fanfiction publics running. A subsequent objective is to elaborate field-specific proposals to enhance copyright law in order to better match the reality of transformative working and publishing in digitized/mediatized social worlds. Against the background of our research, we reflect on the assumptions built into existing law regarding the understanding of fan/art works' originality, ideas of authorship, and economical contexts. In this respect, the project is a contribution to Empirical Legal Studies (ELS) (Reißmann, Klass, \& Hoffmann, 2017).

Of course, we are not the first to tie together research on fan practices and copyright law issues. Benkler (2006), Jenkins (2006), Lessig (2008), or Tushnet (1997), to name just a few academics with very different backgrounds have, for a long time, revealed tensions between fannish creativity and protective legislation. They have argued for the need to reconsider legal frameworks in the era of remix and convergence culture. The particular contribution of an ELS perspective and the point of departure of our project is the conviction that those responsible for political-juridical conditions benefit from more empirical data and results concerning law acceptance and providing a realistic view of actual practice. ELS complements existing "black letter analysis" (of laws and cases as primary sources) and culture-historic, philosophical works on the groundings of legal norms (in our field, e.g., underlying notions of creativity).

\footnotetext{
${ }_{1}^{1}$ For a critical discussion on de Certeau and his reception within fan studies see Hills (2002, pp. 14-15) and also Parrish (2013) who prefers Penley's metaphor of Brownian motion with a focus on processes of world building/world changing over the figure of the nomadic textual poacher.
} 
In Germany, ELS are still in their infancy. ${ }^{2}$ With regard to our field, ELS means to turn attention to the practice of transformative working. This includes the selfassessment and motivations of actors, as well as in the course of everyday life usually non-reflected patterns of justifications, as well as practices of writing, publishing, and technological mediation. While most ELS research follows quantitative, deductive-nomological designs (Chambliss, 2008), our approach is qualitative, oriented towards everyday life action. Our research design combines semi-structured interviews with authors, platform and document analyses (e.g., of platforms' TOS, selected forum discussions/threads, commentary), offline observation (e.g., participation in comic/manga conventions, book fairs), and online-offline ethnography (currently: with a group of women engaged in $\mathrm{RPs}^{3}$ on Stargate Atlantis).

For the purpose of this paper, we focus on three distinguishable but entangled discourses. These discourses concern the nature, principles and core ethics of doing fanfiction. At the same time, each one is linked to specific legal issues. The first and overarching discourse is on fans' will and power to appropriate, and the legal limitations set by, intellectual property. The second is on the collective nature of authorship as a central selfdescription in the scholar fan literature and as a challenge to notions of individual and unequivocally identifiable authorship underlying copyright law. The third is on gift-culture and anti-commercialism as the pivot of community ethics, and likewise is significant for legal assessment. Altogether, the three discourses primarily affect the second meaning of fan (fiction) as acting on the political-juridical conditions, which of course, in turn, include moments of infrastructuring.

Regarding the way of presenting discourses and our own results, we attempt to bring forth a dialogue, using our empirical insights as commentary to ongoing academic and public debates.

In this paper, we-only-draw on qualitative data from the first stage of the interview study. As experts regarding their everyday lives and of fan culture, informants were invited to talk about their life, remarkable experiences and habits as fans and fanfiction authors. In semi-structured interviews, they reported how ideas and texts individually and collectively develop, what they do within fanfiction platforms and other media, as well as what they think about copyright and related questions. So far, the sample is composed of 20 fanfiction authors (19 female: 1 male) aged between 17 and 38 years (as of end of May 2017, more interviews are pending). Eight of them are students at universities in (Western) Germany, four of them are high school students, and one is a trainee. Seven interviewees work and are employed in various fields (e.g., public service, education, psychotherapy, first aid). All names are pseudonyms. Informed Con- sent allows us to store and analyze the transcripts in full and to publish selected quotes under the condition that anonymity of interviewees is guaranteed.

Influenced by the principles of Grounded Theory, we attempt to construct a heterogeneous sample of contrasting cases (Strauss \& Corbin, 1998, pp. 201ff.). Our interviewees actively participate in different fandoms (Naruto, Dragon Age, Yu-Gi-Oh, One Piece, Star Trek, and Supernatural, to mention the most prevalent), cover different genres of writing ("classic" fanfiction, RPG writing, but also "own"/non-derivative stories), and use various media and platforms (with Ao3, fanfiktion.de, and Animexx being the most frequently used; but also, platforms like Tumblr and their own sites are discussed). In order to understand them as individuals, to look for differences and similarities between certain authors, as well as to analyze reported and observed (media) practices and routines of acting beyond a case-centered perspective, we extract confirming and contradictory information through the constant comparison of data. As a means for systemizing the body of texts, we apply strategies of reductive analysis to each interview by applying a category system (worked out inductively by initial open coding as well as deductively by sensitizing concepts and prior knowledge). At first glance, this procedure is more associated with data analysis strategies such as thematic coding or qualitative content analysis (Schreier, 2014) than it is with Grounded Theory. However, for keeping track of the amount of data, we consider this a helpful (nonrigid, open-to-change) tool on the descriptive level and see it as a useful supplement to more contextualized, iterative, and (self-)reflective (Charmaz, 2008) methods of building up theoretical concepts, categories and their interconnections.

\section{Fanfiction and the Power to Appropriate}

\subsection{Discourse and Perspectives}

Epistemologically, appropriation of things (of all sorts) can be seen as a human condition. Using activity theory as an example, through acting with objects and artifacts people incorporate culture-historic practices (Engeström, 1987/2015). Derivative respectively transforming appropriation is not the only, but is an important mode of existing and is associated with creativity and innovation. The question is not if derivative appropriation is something special or new or in particular linked with fan cultures (see Bortolotti \& Hutcheon, 2007, for ancestor/descent-modifications in biology and the transfer to literary adaption theory). Rather the question is, under which cultural, historical and societal circumstances, and in which ways (il)legitimacy to forms of appropriation is ascribed and negotiated.

Unquestionably, currently and the past, fans were regarded to possess the power of meaning-making and

\footnotetext{
${ }^{2}$ It is important to distinguish Empirical Legal Studies from the sociology of law as a discipline concerned with the analysis of lawmaking itself, with law institutions, their working etc.

${ }^{3}$ RP or RPG is short for "Role Play"/"Role Play Game”.
} 
follow-up-communication. Tulloch and Jenkins (1995) regarded fans as being a "powerless elite" (Jenkins, 1992, p. 89) with little direct and self-initiated influence on production processes on the one side, but with "the power to gloss and to write the aesthetic history of the show, (Tulloch) the power to analyze its contents and evaluate its episodes" (Jenkins, 1992, p. 89) on the other side. Fiske (1992) stated that cultural capital is the basis of the economy of fandom. Discussing and commenting critically on a fandom's "canon" 4 is one of the most important characteristic which separates passionate fans from general audiences, and which is also a major motivation to engage in fanfiction (e.g., Thomas, 2006).

In the course of digitalization, convergence and mediatization, fans' opportunities to become visible and to gain access to publics have increased (e.g., Jenkins, 2006, p. 131). To downplay or to render fan criticism invisible is not as easy as before. Fans using platforms like Twitter or their blogs, actually may set agendas and partially influence public debates and framings of series, games or books-such as in the case of the series The 100, in which a lesbian character died, and a discussion on representation of LGBTQ characters within shows emerged; or the recent Hollywood scandals involving whitewashing in movies such as Ghost in the Shell. Beyond that, fans develop also other forms of activism and engagement (e.g., The Harry Potter Alliance, Jenkins, 2014).

At the same time, with changing levels of visibility, new forms of economic absorption emerge. Using the example of Torchwood media tie-ins, Hills (2012) reveals a mode of transmedia storytelling following an industrial and disciplining logic (Hills, 2012, p. 423). According to his analysis, Torchwood's canon producers seek "to preempt fan debates, criticisms and interpretations", to take "back the power to 'gloss"' (Hills, 2012, p. 423) by adding prequels and sequels to the franchise and "symbolically transforming production contingencies into hyperdiegetic continuity" (Hills, 2012, p. 425). Hills calls this industrial absorption a "trans-transmedia storytelling", the second "trans" standing for (transmedia) management of fan discourse.

In Cultural Studies, discourse has always been conceived as being a permanent struggle for power. Whereas meaning-making and to gloss-albeit attempts of absorption-are "rights" nobody can take away, transforming, materially reifying and publicly circulating fan fantasy are highly contested. Relations between those things or elements which should be public domain and those which should be individual property have always been a point of discussion. A common argument put forward by Benkler (2006), Jenkins (2006), Jenkins, Ford and Green (2013), and others, is to accept the (free) circulation and transformation of media contents and forms as a characteristic of convergence and digital culture and to foster the wealth of networks. Already the use of (every- day) notions like "derivative" or "appropriative" is contested, insofar as they can be seen to reproduce normative hierarchies of first and second order artifacts (Derecho, 2006, pp. 63-65).

The asymmetrical legal position and normative hierarchizing in first ("original") and second order ("derivative") artifacts suggests a one-way logic of appropriation: There are those who create source material, as well as those who take and build on source material created by others. But appropriation and inspiration are anything but unidirectional. Also prior to the rise of the WWW and social media, relations between canon producers and fans have been complex. New media simplified the mutual influencing of both groups upon each other. Booth (2010, p. 4) exemplarily highlights early cases of BabyIon 5, X-Files, Battlestar Galactica, and Heroes. For each of these series, online fan input and feedback in one way or another influenced professional production. A more recent case is the integration of online fan speculation in an episode of BBC's Sherlock, in which the authors addressed fan-speculations and the act of speculation itself.

Academic fan studies may self-critically discuss their bias in subordination theorems (Hills, 2002, pp. 14-15; Parrish, 2013). And of course, just by making fanfiction, just by actually establishing their own infrastructures and circulating works, fans exert power. In doing so, fans cannot solely be conceived as "nomads" or "poachers". However, legally, fans remain in a weak position. First, due to the fact that they in most cases do not own the material they build on. Secondly, due to the fact that (national) legal windows are rather narrow and/or not outlined in a clear way. For example, in most cases fanfiction cannot be determined as "parody". Other exceptions like the often-mentioned United States (US) "fair use" (raised already by Tushnet in 1997 as a political claim) based on rather vague criteria and a lot of preconditions (e.g. Fiesler \& Bruckman, 2014), leading to immensely interpretive flexibility and therefore to legal uncertainty.

Beyond that, underlying notions of "originality" in copyright law are challenging. In German "Urheberrecht" ("author's rights"), an important differentiation is that between "freie Benutzung" ("free use") and "unfreie Bearbeitung" ("non-free adaptation") (= §23 UrhG-§ 24 UrhG). This differentiation is used to distinguish between admissible inspiration and inadmissible exploitation of other authors' rights. An indicator for or against copyright infringements is the degree of "fading" ("verblassen") of the source text's individual characteristics in the derivative work. Although discussions on remix practices as essential parts of particular ("postmodern") art forms are spurred by recent jurisdiction on sampling, ${ }^{5}$ the existing legal framework was not built for transformative works whose punchline-as in fanfiction-is not fading and is not distant to the primary text, but is visi-

\footnotetext{
${ }^{4}$ Whereas "canon" in fan slang stands for the totality of officially media texts published by professional/commercial media industry within a certain universe/story (e.g., Harry Potter), "fanon" is short for all fan works building on the canon.

5 “Metall auf Metall", BVerfG, 31 May 2016-1 BvR 1585/13.
} 
bly and recognizably similar to a certain story or character's features.

Therefore, and besides informal practices of toleration, fans still are dependent on the good-will of copyright holders and their agencies, as well as having to cope with the situation of acting within a gray area.

\subsection{Data-Based Commentary}

While it is rather easy to proclaim whether public circulation of fanfiction should be legalized or should be prohibited, following the approach of ELS outlined above many questions arise: How do the authors look at and justify their actions? What are they actually doing with the source material and others' ideas? Do they want their own creations to be protected or not? In which relationship does self-assessment, rationalized action and practice occur? And finally, what conclusions can be drawn from that regarding the revision of copyright law?

As yet, we have no definitive answers to any of these questions. However, we can add empirical-based reflections on selected issues. Besides routinized practices of disclaiming and demonstrating respect to canon creators, our interviewees focus on the handling of the source material. In most of the cases, being involved in fanfiction is inevitably linked to the desire to extend the public domain, to being allowed to write and publicly circulate stories. This claim is often justified by the absence of commercial intentions and by making the author's sources of inspiration transparent. At the same time, this does not mean that ideas of intellectual property would vanish or not relate to acting and thinking anymore. While some argue that writing in general and fanfiction, in particular, are all about borrowing and using what someone else created and therefore present a liberal point of view, whereas others identify themselves as being the creators of unique characters, details, and story worlds, which they want to protect from exterior influences. Likewise, we notice a strong bond between authors and their work, not least due to time and effort they have had to spend on it. Interviewees speak about their creations as "my story" or "my character". Although little attention is paid to the "original" authors' attitudes, awareness of what others could do with their own creative works is rather high. While in principal, almost all of our interviewees would accept a second-level-appropriation of their own (fanfiction) works, they insist on being referred to as a creator, and on a non-commercial character of the appropriation. ${ }^{6}$ At least, holding and defending a visible position in an imagined row regarding referencing and (re-)appropriating seems to be significant.

It is no surprise that the act of looking into appropriation practices evokes ambiguous results. Furthermore, the methods and objects of adaptations and transforma- tions are immensely diverse. While analyzing and contrasting the material, four provisional approaches towards changing the source text become clear.

The first approach is particularly careful with the source text and refuses to implement broad shifts in the original stories. Above all, authors want to create small side stories, which complement the canon rather than change it. Regarding the willingness to change an original story one author states: “It isn't in the nature of the thing itself because the characters are how they are" (Patricia, 26). The constructed stories have to fit in the given story world created by the original authors: "I wrote stories that weren't in the book. Not that they were missing, but they weren't really there" (Talea, 17). Following this approach, the fixed nature of beloved characters is highlighted. It is important that characters and their unique traits are easily recognizable.

The second approach also highlights the importance of a consistent character development, where the source material and the fanfiction texts are complementary to each other. But in contrast to the first type, authors are more willing to allow exceptions as long as the implemented transformations serve a higher creative value:

There is the will to portray the characters as they are. This was always important for me. But this is possible in a limited way. Because if you want to change a heterosexual character into a homosexual one you automatically change character traits. You have to deal with that. (Eva, 29)

As with the first type, the second type also cherishes the original characters but understands them more as tools to realize a unique creative vision. Here, authors have a more playful approach and are not afraid of making bigger transformations. Frequently, the characters themselves seem to push the authors to make such transformations, because "characters sometimes develop a life of their own" (Eva, 29).

The third approach is more critical in working with the source material. Authors do not see the story world and the characters as fixed entities. However, in comparison to the second type, they approach the source material more sincerely and less playfully: "I love Marvel beyond anything else, but at the same time I perceive it often as sexist" (Hannah, 17). In this case, the transformation of the source material can be seen as a way to save a beloved text and/or as a form of ideological critique. Authors feel an obligation to perform radical changes. Following this approach, work improvement is understood as taking a critical stance and increasing diversity. Authors oscillate between affection and criticism, because "the first motivation is always the love for a text" (Sonja, 38).

\footnotetext{
${ }^{6}$ Similarly, Busse and Farley (2013) report the case of a challenge within a LiveJournal community on Stargate Atlantis in 2006 whose initiators allowed to use work of other fanfiction authors-with or without their permission. Due to the supplement, the announcement "reached more than a hundred responses within hours, mostly complaints" (Busse \& Farley, 2013, online). The opportunity of writing fiction on the basis of others' fanfiction without permission was experienced as a violation of community norms by most members.
} 
In the fourth approach, the source text is used as a starting point to develop new stories. Alleged weaknesses are seen as opportunities: "The original story had so-called plot holes, you can do a lot of things with it" (Xara, 21). Here, the relationship towards the source material can be seen as functionalistic, without many restrictions: "While writing stories you are completely free" (Pawel, 25). The weaknesses of the source texts are seen as a stepping stone to go further from the original text to create new story worlds, which can veer far from the source material.

From the very start, looking out for weaknesses in storytelling and the will to improve and change stories because of plot holes, inconsistencies, "badly" or insufficiently drawn characters and their specific relations was stimulating fan fantasy and fannish extensions (e.g., Jamison, 2013, pp. 42ff. on early Sherlock Holmes fanfiction). Yet, the heterogeneity of transformations we find invites us to reflect on the legal status quo. According to copyright law in Germany, one important criterion of assessment would be the degree of "fading" (see above) and the distance to the source text. Probably a " 4 th approach"-author would be better able to argue that she or he had added sufficient creative value. However, all those different authors working on different aspects with different styles are still doing the same: fanfiction. Does the established assessment procedure for identifying copyright infringement really catch the core of creative appropriation in fanfiction and other fields of derivative works? Under certain circumstances, it may just be a detail, a single character trait, which is decisive to be able to recognize and appreciate a story as being unique or creative. There is need to sensitize law for "postmodern" modes and forms of creativity which go beyond classical understandings.

\section{Fanfiction and Collective Authorship}

\subsection{Discourse and Perspectives}

Just as appropriation, the collectivity of doings and makings can be seen as a human condition. Taking ActorNetwork-Theory (Latour, 2005) as an example, it is an epistemological decision to regard the interaction of things and humans as inevitably collective. Following the concept of "distributed cognition", developed in science studies by Hutchins and colleagues (e.g., Hutchins \& Klausen, 1996), cognition is not seen as being located at the individual level, but radically distributed, based on networked relations and processes involving various (human) actors as well as materialities and technologies. Therefore, the question is not, if writing or publishing are collective acts involving and assembling heterogeneous materials and humans. Rather it is to ask, in which ways writing and publishing collectives make themselves visible and accountable as collectives (or not), and to what extent existing law is capable and/or is societally enforced to cope with different forms of collectivity.
From its very beginnings, fan studies emphasized the collective dimension of fannish activity; of course, primarily as a matter of human interaction. Besides preconfiguring social contextualization of reading popular media texts or nonverbal forms of "enunciative productivity" like dressing (Fiske, 1992, p. 38), in-situ-sociality of watching, discussing and experiencing movies and videos, playing games, joint listening to music, going to concerts or visiting other media places such as cinemas, discotheques, clubs etc. was emphasized. It is no accident that concepts of "(media) scenes" or "youth (media) cultures" are important means for explaining fan activities in terms of social and cultural belonging and joint doing.

Entangled with utopian visions of early net culture, the collective dimension of fannish activities acquired additional connotations. When addressing the consequences of new media and communication infrastructure on fan communities, around the millennium, scholars such as Baym (1999), Jenkins (2002) and Hills (2002) reflected on a huge range of topics: e.g., changing temporalities in order to follow media fandoms in line with rhythms of publishing and broadcasting; changing socio-spatial patterns of reading and watching; changing scopes of communication and interaction flows transcending local and national borders; or emerging opportunities of (simultaneously) discussing broadcasting in online forums (later called "second screen"), as well as of the gathering and storing of fan productions in online archives.

For coping with digital media's affordances towards collectivity, Jenkins (2002) drew on Lévy's (1994/1997) "collective intelligence". Retrospectively, we may criticize accounts like this to their slight euphemistic touch and social romanticism towards digital culture as being an alternative sphere of its own. Yet, more important is that the thought of knowledge communities putting "collective" or "connected intelligence" (de Kerckhove, 1997) over the limitations of individual thinking and acting is a strong and lasting narrative. They materialize in concepts of "swarm intelligence/smart mobs" (Rheingold, 2003), and are important ideological groundings for collaborative communities such as Wikipedia.

In none of its meanings and readings, should collective doing be mixed up with communitarian ideals of consensus or harmony. In fact, community ethics and values of how to interact with each other are important (e.g., regarding non-intended spoilers, acknowledging and respect other authors' efforts and works). At the same time, conflicts and differing points of view, norms and ideals between communities and fandoms as well as within communities and fandoms are part of the game as well (for early recognitions of conflicts in online fan communities, see Baym, 1999; Jenkins, 2002; McDonald, 1998).

In fanfiction, utopian visions of digital culture converged with pre-existing feelings of belonging to a certain community and fandom. Fanfiction is often equated with 
the idea of collective authorship. The "person we like to call the author, is not a single person but rather is a collective entity" (Busse \& Hellekson, 2006, p. 6). Taking this statement as the point of departure, we can proceed in at least two ways:

A first reading of collective authorship extends literary tropes such as Barthes (1967/1994) "death of the author". ${ }^{7}$ By shifting from the author to the reader and to reception processes as locus of meaning making, Barthes and others questioned and deconstructed the myth of the individual author as a genius or author-god. Although in fanfiction, readers are also frequently authors at the same time, co-creation is an inevitable disposition of text emergence. This is not necessarily associated with a decline in authorship (as a value), but underlines the collectivity of authorship: Nobody owns texts and ideas alone-nobody produces them on his or her own alonenobody can fix meaning alone.

A second way of understanding collective authorship is much more literal. Inverting traditional ideas of individual authorship which tend to make factual collectivity invisible, fanfiction communities ostentatiously celebrate and demonstrate joint doing. This includes practices of "beta-reading", feedback and commentary, a widely-shared view of texts as never-finished "work in progress" (Busse \& Hellekson, 2006; Derecho, 2006). This includes work and invested time and effort of all those, building up, maintaining and filling WiKis (such as Fanlore or Wookieepedia) or devotional fan sites and blogs, writing "metas" (narrative analysis) or participating in mailing lists, discussion boards etc. This includes collective "textual performance" (Hills, 2002, pp. 16-19; Lancaster, 2001) and playful practices of transformative reenactment, especially in role play stories.

Against that background, fanfiction scholars like Busse and Hellekson (2006, p. 7) define the "fantext" as "the entirety of stories and critical commentary written in a fandom", offering "an ever-growing, ever-expanding version of the characters" - "this multitude of stories creates a larger whole of understanding a given universe", and "every new addition changes the entirety of interpretations". Drawing on Derrida, Derecho (2006, p. 64) prefers the term "archontic" over "derivative" or "appropriative literature". The latter ones "announce property, ownership, and hierarchy", whereas "archontic" is seen as being "not laden with references to property rights or judgments about the relative merits of the antecedent and descendant works" (Derecho, 2006). First and foremost, the archontic principle is about expanding, and we might add: This expansion is a collective enterprise.

\subsection{Data-Based Commentary}

The capability of copyright law to grasp authorship beyond the individual is not so much a matter of quantity or abstractness of personhood. Law neither considers the number of individuals asserting a claim to authorship (this paper has 5 , a physics paper may have over 20 authors), nor does law have difficulties treating groups or organizations as liable entities (corporate personhood as a legal fiction). The question is, in which ways complex participations in authorship make themselves accountable, and if and how distributed authorship, property, and liability can and should be implemented in law.

To better grasp collective moments in processes of text production, we adopt a procedural perspective on writing and publishing fanfiction stories (leaving aside role play stories):

In the initial or planning-stage, the main task our interviewees report is the search for inspiration. This can be found from the reading of others' fanfiction, by an active reception of the original (media) texts, from the collection of background information (on characters, narratives or topics provided by other fandom members, e.g., in Wikis), or through discussion with friends and community members. Individual modes differ but often have a collective component. Some need prompts from the community to get into the writing process. Others extensively read stories from their nearest friends to start a discussion about strengths and weaknesses in previous works. Hannah (17) and her friends resemble the concept of the writer's room: ${ }^{8}$

We had some weird ideas and had five different characters, like Captain Jack Sparrow and Neil Patrick Harris, put them together and created a story out of this, which [name of her friend] wrote down and developed further.

Of course, not everyone is as networked or interacts to the same degree. Furthermore, some biographical notes reveal a gradual growth into more collaborative modes of mutual support and inspiration, where initial stories were more or less written solely by individuals and simply uploaded. Also, the complexity and length of stories are not to be underestimated as a factor. Where "one shots" (stories consisting of a single chapter only) may be written in a very short time, long-time projects involve people for several weeks, months, sometimes years, accompanied by dozens of discussions and modifications in the meantime.

Describing writing processes in terms of stages is no more than an analytical tool. Often works in different stages are processed at the same time, and stages blur, when circles of planning, writing, publishing and commenting (after publication) accelerate. This is especially true for the step-by-step publication of single chapters. Bearing that blurring in mind, the second stage is the writing itself. More data may change our findings in this respect. Until now, writing has been reported as

\footnotetext{
7 See Sandvoss (2007) for a general discussion of the relation of cultural/fan studies and literature studies, including questions on aesthetic value.

${ }^{8}$ The concept of the writer's room is about establishing a playful atmosphere for television storytelling. New ideas are developed in collective thinking processes and put into practice by the best writer(s) in the group.
} 
being an intimate and rather lonely experience. It has been described as a deeply personal creative act, where authors want to realize their individual ideas on their own terms. Others come into play again after finishing first drafts. This is the stage of revision, which often employs friends and acquaintances as "beta-readers" prior to publication:

She uploaded Word-Documents on Facebook and we downloaded them and wrote our comments with red into them and corrected everything we came up with. (Talea, 17)

Drafts are exchanged via email or social media platforms such as Facebook. Mostly, commenting and revising refers to formal mistakes: "not really the plot of the story, but mainly stuff like spelling or grammar" (Talea, 17).

What follows, is the publishing and the implementing of the stories into online platforms. Often headers and short descriptions are used to refer to beta-readers and inspirations that influenced the work. Following the publishing of a chapter or an entire story, commenting and (online) feedback begins. Sometimes, comments and follow-up-associations lead to new ideas or influence further chapters. The handling of comments differs from author to author. While some writers appreciate constructive criticism leading to intriguing and helpful discussions about the written text, others complain about the lack of quality commentary. However, all authors express a positive attitude towards useful feedback:

Yes, they have really dealt with the story and I prefer that over commentators, who only write "Continue your story the fastest way possible!" I am happy about this. (Xara, 21)

Constructive criticism heightens the motivation to continue stories or to develop new ones. Beyond that, interviewees often speak about a learning-curve regarding their skills. They either received feedback that helped them to grow as an author or simply became better through the quantity of writing that they had produced.

Reading, following other's work, inspiration from sundry sources, shared emotional support, commentary and feedback - put together, all these moments light up as a spiral of collective and distributed creation with various people and media involved. A closer look at writing genres like role play stories (we give greater attention to it in our ongoing data analysis) reinforces the collective dimension of making fanfiction: Role play stories are associated with collective authorship per se, are often performed together in situ, and demand a high act of collaboration because of writing in rotation and having to negotiate the rules of the game. ${ }^{9}$

Against that background, we may critically question the law's bias regarding "individualized" imaginations of authorship (see, e.g., Dulong de Rosnay, 2016, for thoughts on applying "peer to peer" principles to the design of law institutions). Is it not rather the distributed collective, the assemblage, who acts? While thinking along these lines, one also needs to take into account the fact that actual production processes and practices of ascribing (quasi-)legal authorship and responsibility are not the same. Not only the law but also most of our interviewees as well as the mainstream architecture of fanfiction platforms and related media services continue to be biased in concepts of individual authorship. In most of the cases it is one specific author (respectively persona) who uploads a story and is displayed as the author by personalized accounts and profiles. Paradoxically, large parts of the collectivity that exists is rendered invisible with the help of the infrastructure which was built for and by communities who value the collective over the individual. Furthermore, in many interviews collectivity of text production is highlighted and at the same time individual authorship remains an unquestioned basis of thinking about oneself as a creative actor. Our findings indicate various forms of cooperation in text emergence and several ways of making cooperation explicit. However, further efforts are needed to investigate the relations between making cooperation visible and invisiblealso with regard to the shape of media infrastructures in use.

\section{Fanfiction and Gift Culture}

\subsection{Discourse and Perspectives}

Intersections of commodity culture, consumerism and fan culture are issues which have been discussed frequently. Whereas the initial, mainly structuralist accounts in Cultural Studies tended to construct "subcultural" practices (of youth) in opposition and resistance to hegemonic consumer culture, emphasizing complex and contradictory relations between fan and commodity culture is commonplace today. This goes for principal questions on the (im-)possibility of fan agency in relation to cultural industries as well as for questions on the hybridization and blurring of spaces, actors and spheres of production and consumption (for a critical reflection of academic accounts on power relations within fan studies see Hills, 2002, pp. 3-19). The question is not if fan and commodity culture are two sides of the same coin. Rather it is to ask, in which ways relations to commodity culture are part of the self-understanding and justification patterns of fan cultures and how these narratives relate to actual practice.

With respect to fanfiction, dominant ethics and motivations are often described with reference to the concept of gift culture (De Kosnik, 2009; Hellekson, 2009). Following this approach, authors write and circulate stories for joy in the first place, without any kind of re-

\footnotetext{
${ }^{9}$ So far, our material indicates a struggling of players between self-imposed ideals of collective (inter-)acting with having equal rights, and a "reality" of writing and planning involving colliding interests and fantasies.
} 
ciprocal obligation. This understanding may differ from sociological and anthropological accounts of gift-giving (e.g., Bourdieu, 1994/1998; Mauss, 1950/1966). However, in our opinion, the ambivalence of gift-giving as an allegedly unconditional practice and a veiled claim on (time-lagged) reciprocity also goes for popular culture. On one hand, fanfiction community ethics imply giving and sharing without expecting a reward at all. In this sense, they are associated with ideas of altruistic ways of living. On other hand, stories can also be seen as a vehicle for givers to receive something in return; not necessarily immediately, not necessary in an equivalent form-but at some time and in some way, even though the "reward" may only be valuable experience.

From a more global perspective, the strong emphasis on non-commercialism in fanfiction communities, and the cultural construction of "gift and commercial models as discrete economic spheres" also serve "as a defensive front to impede encroaching industrial factions" (Scott, 2009, online).

Another rather ignored reading of gift culture reflects on the metrification of various fanfiction-related actions in digital platforms, and the ways of how displaying and interacting with data and statistics (views, likes, rates, amount of comments etc.) shape culture and community ethics. Taken literally, economic exchange is mediated by currencies. Besides classic models of monetary transaction, attempts were made to characterize the online or digital economy as "attention economy" (e.g., Davenport \& Beck, 2002) or "digital reputation economy" (Hearn, 2010). Against that background, we may assume a version of gift culture within fanfiction (as in any other part of digital culture and sociality) that hinges on measurable, quantifiable and representable amounts and rankings of received attention. This is not to say that individuals are "monolithic agents", as Benkler (2006, pp. 92ff.) illustrates in his reflection on models of motivation and relations of money and social-psychological rewards in digital culture. However, a closer look at different readings of "gift culture" reveals that boundaries between an ostentatiously non-commercial habitus and "quasi-commercial" acting are fuzzy. Beyond fanfiction, Booth (2010, pp. 24ff.) coined the term "Digi-Gratis". This metaphor is helpful to grasp the blurring of commodity and gift economies. Translated to fanfiction: stories, blog entries etc. are given for free. It is not necessary that readers pay for the content, nor that they "answer" on an equivalent level with their own stories or blog entries. However, it is expected that they leave comments, likes or other signs and hints to let it be known that somebody has taken notice of what has been read, heard or watched.

From another angle, "gift culture" is problematized with regard to rewards of third parties. As in other fields of digital culture (e.g., Terranova, 2000), critical arguments reflect on the "exploitation" (a difficult horse to catch, of course, with its semantics of forced ac- tion) of fans" "free labor" (e.g., De Kosnik, 2012; Stanfill \& Condis, 2014) ranging from inspiration for professional cultural industries to analysis of user content and user profiles (e.g., for enhanced definition of target groups and marketing strategies) to the revenues that archive sites are able to achieve through advertising or paid accounts. Therefore, some scholars who have foreseen attempts to monetize fanfiction (e.g., Scott, 2009) posed (self-)critical questions regarding the participation of fans in profits, and on fannish control and power of influencing emerging business models. These debates have (re-)intensified ${ }^{10}$ more recently with the rise of new licensing models in platforms such as Amazon Kindle Worlds (e.g., Hellekson, 2013).

\subsection{Data-Based Commentary}

Looking at discourses and assessment procedures regarding copyright infringements, the presence or absence of economic damage for copyright holders and agencies, and the commercial or non-commercial motivation of actors, are not the only, but are important criteria. With the growth of the field, more than ever consisting of heterogeneous groups with very different intents and habits, with the emergence of new role models such as the commercial success of Fifty Shades of Grey, and with the appearance of commerce-driven platforms, we ask whether the boundaries of "gift culture" become permeable, and how different economic styles and forms of capital are interconnected in digital fan cultures.

It is very clear that our interviewees do not see themselves as commercial actors. In this respect, we can confirm what many studies have found: People keep saying that writing fanfiction is a hobby in the first place. They expect neither money nor any physical rewards. They offer their fanfiction for the group of people they feel part of. What they get back is attention and recognition in form of comments or Likes (e.g., Kudos in Ao3). Comment regarding commercial platforms such as Amazon Kindle Worlds (if interviewees know of it) is critical. Earning money is seen as threatening the beloved culture rather than being a helpful innovation or giving added value.

Beyond commercialization in the narrower sense, two findings are worth reporting, however. First, writing fanfiction (as a hobby) and writing "non-derivative" stories (possibly as profession) are distinct and related social worlds. Most of the interviewees are doubtful with respect to the skills gained, thinking that the quality of their stories is not fit for professional writing. Yet, this does not mean that some of them would not toy with the idea of becoming a "real" author or would not make the first steps to establish themselves as such. Patricia (26), for instance, published three edited books with friends, mixing manga drawings and stories. Fanfiction is both a playground and a training camp. While fanfiction itself should remain l'art pour l'art gift culture, it is also perceived as

\footnotetext{
${ }^{10}$ A first wave of discussion hinged on the rise and fall of the platform Fanlib around 2007.
} 
a ticket to other areas of writing culture associated with different rules and norms. While fanfiction and payment seem to rule one another out, none of our interviewees think fundamentally bad about earning money with professional writings for official (online/print) book markets. Instead, money-making - here-is taken-for-granted and remains unquestioned:

There are a lot of artists on Animexx who publish their stories parallel [online], but also let them be printed....and offer them for sale. And uh if they are really good I would buy it, or rather wait until it is made into a bundle and then I would get that if I wanted to re-read it a lot. So, I definitively think a market should open so that people have the opportunity to print their work, especially since the quality, here in Germany, became better over time. (Patricia, 26)

Introducing these findings here is not to say that fanfiction is a preliminary stage of economical acting and therefore is to be regarded as economic-driven itself. On the contrary, our data indicate separated social worlds with different rules. However, if the objective of our research is to untangle a complex picture of transformative writing and publishing, and to better understand subsequent economic chains, these interconnections are part of the picture. This is also true the other way round, as some publishers screen online markets and platforms in order to explore existing or potentially successful stories and authors.

Secondly, we find evidence that platforms' quantifying feedback logics influence the acting of certain authors. As previously mentioned, feedback is the most important means of regifting and showing respect for authors' efforts and labor. Accordingly, so-called "Schwarzleser" (an often-used German expression for "lurker" who only read and do not give feedback) are anything else than welcome. Conversely, even though this is (on the reflexive level of semi-structured interviews) more of an exception, authors and readers do have a sense of quantity. They look at and know about how many comments or Likes fanfiction gets. In few instances, a motivation is to reach a certain quantity of reads and feedback in what can be interpreted as a form of quasicommercial acting.

More efforts are needed to grasp the commercial complexities. In which ways (or not) is media capital (in form of attention or quantity of followers) part of fanfiction's digital economy? Can this kind of capital be exchanged or transferred? If at all, who profits? What are the future business models of publishers and platforms towards fanfiction? Will they be game-changers? Until now, it has been difficult to find answers to these questions. However, the discursive demarcation of noncommerciality as a form of collective self-protection and an informal/latent agreement between industry, law, and fans, may turn out as being too narrow in future. With increasing attempts to commercialize fanfiction and other fan works, with heterogeneity of mediating platforms, infrastructures and commercial logics-fan actors, as well as proponents of fair legal regulations, should ask why of all things should anti-commerciality be the life insurance for transformative working.

\section{Conclusion}

Fanfiction is acting on media in at least two ways. By infrastructuring communities and publics, authors, readers and platform runners build up (own) communicative and (quasi-)material spaces for circulating, sharing and archiving the stories they want to write and read, for the stories they cannot find in official canon productions. By doing fanfiction, whether it is their intention or not, they also question the existing political-juridical conditions which frame transformative working and publishing of derivative material. Fanfiction challenges prevalent concepts of individual authorship and proprietary of cultural goods.

Discursive demarcations in debates on copyright law (e.g., Lessig, 2008) range somewhere between protectionism of individual authorship and right holders, and the proclamation of free culture and public domain. The attempt of our project is ultimately to back normative legal positions and underpinnings by empirical research on the "reality" of derivative/transformative working. On the basis of our preliminary findings we-so far-can state that authors' explicit and tacit practice is as least as complicated as the political-juridical struggle of interest groups on the political stage. This goes for all of the three debates discussed and empirically commented on in this paper. Our findings indicate a desire to legalize fanfiction (or better: to engage in it without fear, and with legal certainty) and to get the legal field ready for complex participations and distributed authorship. At the same time, we identify the practical reproduction of traditional ideas. Self-understandings, justification patterns and doings seem to both partially oppose and to partially reproduce the logic of first and second order artifacts; they seem to partially celebrate the visibility of both collective and distributed authorship, to partially reproduce the myth of the individual creator; to partially oppose economic thinking as well as to partially reveal related forms and connected social worlds.

Contradictory practices, narratives, and justifications can be found within fanfiction. Informed by practice, ELS have to cope with those ambivalences and balance out recommendations thoroughly.

\section{Acknowledgments}

The research project "Media Practices and Copyright Law" is funded by the German Research Foundation (DFG) as part of the Collaborative Research Center 1187 "Media of Cooperation" (University of Siegen). We like to thank the Center for supporting this publication, and the anonymous reviewers for helpful commentary. 


\section{Conflict of Interests}

The authors declare no conflict of interests.

\section{References}

Barthes, R. (1994). The death of the author. In D. Graddol \& O. Boyd-Barrett (Eds.), Media texts: Authors and readers. A reader (pp. 166-170). Clevedon: Open University. (Original work published 1967)

Baym, N. (1999). Tune in, log on: Soaps, fandom and online community. New York, NY: Corwin.

Benkler, Y. (2006). The wealth of networks: How social production transforms markets and freedom. New Haven, $\mathrm{CT}$, and London: Yale University Press.

Booth, P. (2010). Digital fandom. New York, NY: Peter Lang.

Bortolotti, G., \& Hutcheon, L. (2007). On the origin of adaptations: Rethinking fidelity discourse and success-Biologically. New Literary History, 38(3), 443-458.

Bourdieu, P. (1998). Practical reason. On the theory of action. Stanford, CA: Stanford University Press. (Original work published 1994)

Busse, K., \& Farley, S. (2013). Remixing the remix: Fannish appropriation and the limits of unauthorised use. M/C Journal, 16(4). Retrieved from http:// journal.media-culture.org.au/index.php/mcjournal/ article/view/659

Busse, K., \& Hellekson, K. (2006). Introduction: Work in progress. In K. Hellekson \& K. Busse (Eds.), Fan fiction and fan communities in the age of the internet. New essays (pp. 5-32). Jefferson, NC: Mc Farland \& Company.

Chambliss, E. (2008). When do facts persuade? Some thoughts on the market for "Empirical Legal Studies". Law \& Contemporary Problems, 71, 17-39.

Charmaz, K. (2008). Constructionism and the grounded theory method. In J. A. Holstein \& J. F. Gubrium (Eds.), Handbook of constructionist research (pp. 397-412). New York, NY: The Guilford Press.

Cuntz-Leng, V., \& Meintzinger, J. (2015). A brief history of fan fiction in Germany. Transformative Works and Cultures, 19. doi:10.3983/twc.2015.0630

Davenport, T. H., \& Beck J. C. (2002). The attention economy. Understanding the new currency of business. Cambridge, MA: Harvard Business Press.

De Certeau, M. (1984). The practice of everyday life. Berkeley, CA: University of California Press.

De Kerckhove, D. (1997). Connected intelligence: The arrival of the web society. Toronto: Somerville House.

De Kosnik, A. (2009). Should fan fiction be free? Cinema Journal, 48(4), 118-124.

De Kosnik, A. (2012). Fandom as free labor. In T. Scholz (Ed.), Digital labor: The Internet as playground and factory (pp. 98-111). New York, NY: Routledge.

Derecho, A. (2006). Archontic literature: A definition, a history, and several theories of fan fiction. In K.
Hellekson \& K. Busse (Eds.), Fan fiction and fan communities in the age of the Internet (pp. 61-78). Jefferson, NC: McFarland.

Dulong de Rosnay, M. (2016). Peer to party: Occupy the law. First Monday, 21(12). doi:10.5210/ fm.v21i12.7117

Engeström, Y. (2015). Learning by expanding. An activitytheoretical approach to developmental research (2nd ed.). Cambridge: Cambridge University Press. (Original work published 1987)

Fiesler, C., \& Bruckman, A. (2014, February). Remixers' understandings of fair use online. CSCW 2014. doi:10.1145/2531602.2531695

Fiske, J. (1992). The cultural economy of fandom. In L. A. Lewis (Ed.), The adoring audience: Fan culture and popular media (pp. 30-49). New York, NY: Routledge.

Hearn, A. (2010). Structuring feeling: Web 2.0, online ranking and rating, and the digital reputation economy. Ephemera: Theory and Politics in Organisation, 10(3/4), 421-438.

Hellekson, K. (2009). A fannish field of value: Online fan gift culture. Cinema Journal, 48(4), 113-118.

Hellekson, K. (2013). Kindle worlds and fan fiction. Retrieved from http://khellekson.wordpress.com/ 2013/05/23/kindle-worlds-and-fan-fiction

Hills, M. (2002). Fan cultures. London: Routledge.

Hills, M. (2012). Torchwood's trans-transmedia: Media tie-ins and brand 'fanagement'. Participations, 9(2), 409-428.

Hutchins, E., \& Klausen, T. (1996). Distributed cognition in an airline cockpit. In Y. Engeström \& D. Middleton (Eds.), Cognition and communication at work (pp. 15-34). New York, NY: Cambridge University Press.

Jamison, A. (2013). Fic: Why fanfiction is taking over the world. Dallas, TX: BenBella Books.

Jenkins, H. (1992). Textual poachers. Television fans \& participatory culture. London: Routledge.

Jenkins, H. (2002). Interactive audiences? The "Collective Intelligence" of media fans. In D. Harries (Ed.), The new media book (pp. 157-170). London: British Film Institute.

Jenkins, H. (2006). Convergence culture. Where old and new media collide. New York, NY, and London: New York University Press.

Jenkins, H. (2009). Critical information studies for a participatory culture (part two). Retrieved from http://henryjenkins.org/2009/04/what_went_wrong _with_web_20_cr_1.html\#sthash.YQxvFJLN.dpuf

Jenkins, $\bar{H}$. (2014). Fan activism as participatory politics. The case of the Harry Potter alliance. In M. Ratto \& M. Boler (Eds.), DIY citizenship. Critical making and social media (pp. 65-74). Cambridge and London: MIT Press.

Jenkins, H., Ford, S., \& Green, J. (2013). Spreadable media. Creating value and meaning in a networked culture. New York, NY: New York University Press.

Kannengießer, S., \& Kubitschko, S. (2017). Acting on media: Influencing, shaping and (re)configuring the fab- 
ric of everyday life. Media and Communication, 5(3), 1-4.

Lancaster, K. (2001). Interacting with "Babylon 5": Fan performances in a media universe. Austin, TX: University of Texas Press.

Latour, B. (2005). Reassembling the social. An introduction to actor-network-theory. Oxford: Oxford University Press.

Lessig, L. (2008). Remix. Making art and commerce thrive in the hybrid economy. London: Bloomsbury.

Lévy, P. (1997): Collective intelligence. Mankind's emerging world in cyberspace. New York, NY, and London: Plenum Trade. (Original work published in 1994)

Mauss, M. (1966). The gift. Forms and functions of exchange in archaic societies. London: Cohen \& West LTD. (Original work published 1950)

McDonald, A. (1998). Uncertain utopia: Science fiction media fandom and computer-mediated communication. In C. Harris \& A. Alexander (Eds.), Theorizing fandom: Fans, subculture, and identity (pp. 131-152). New York, NY: Hampton Press.

Parrish, J. J. (2013). Metaphors we read by: People, process, and fan fiction. Transformative Works and Cultures, 14. doi:10.3983/twc.2013.0486

Reißmann, W., Klass, N., \& Hoffmann, D. (2017). Fan fiction, Urheberrecht und empirical legal studies. POP. Kultur \& Kritik, 6(1), 156-172.

Rheingold, H. (2003). Smart mobs. The next social revolution. London: Basic Books.

Sandvoss, C. (2007): The death of the reader: Literary theory and the study of texts in popular culture. In J. Gray, C. Sandvoss, \& C. L. L. Harrington (Eds.), Fandom: Identities and communities in a mediated world (pp. 19-32). New York, NY: New York University Press.

Schreier, M. (2014). Qualitative content analysis. In U. Flick (Ed.), The SAGE handbook of qualitative data analysis (pp. 170-183). London: Sage.

Scott, S. (2009). Repackaging fan culture: The regifting economy of ancillary content models. Transformative Works and Cultures, 3. doi:10.3983/ twc.2009.0150

Stanfill, M., \& Condis, M. (2014). Fandom and/as labor. Transformative Works and Cultures, 15. doi:10.3983/ twc.2014.0593.

Strauss, A. L., \& Corbin, J. M. (1998). Basics of qualitative research: Techniques and procedures for developing grounded theory. London: Sage. (Original work published 1990)

Terranova, T. (2000). Free labor: Producing culture for the digital economy. Social Text, 2(18), 33-58.

Thomas, A. (2006). Fan fiction online: Engagement, critical response and affective play through writing. Australian Journal of Language and Literacy, 29(3), 226-239.

Tulloch, J., \& Jenkins, H. (1995). Science fiction audiences: Watching Doctor Who and Star Trek. London: Routledge.

Tushnet, R. (1997). Legal fictions: Copyright, fan fiction, and a new common law. Loyola of Los Angeles Entertainment Law Journal, 17, 651-686.

\section{About the Authors}

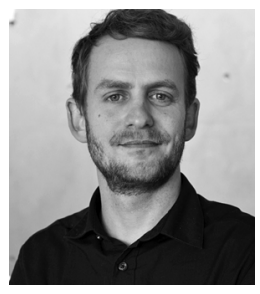

Wolfgang Reißmann studied Communication and Media Studies, History and Philosophy at the University of Leipzig and the Universidade Católica Portuguesa in Lisbon. In 2013, he received his PhD from the University of Erfurt. Since 2016 he has been a postdoctoral researcher in the project "Media Practices and Copyright Law", conducted at the Collaborative Research Center "Media of Cooperation" (University of Siegen).

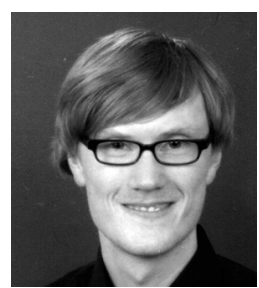

Moritz Stock holds a MA and studied Sociology and Psychology at the Friedrich-Schiller-University in Jena as well as Sociology and Social Research at the University of Bremen and the Åbo Akademi in Turku/Finland. Since 2016 he has been a research assistant in Media Studies at the University of Siegen and associated with the project "Media Practices and Copyright Law", conducted at the Collaborative Research Center "Media of Cooperation" (University of Siegen).

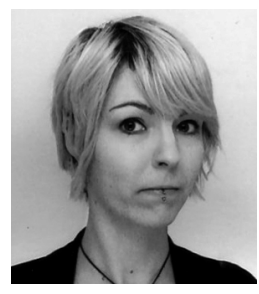

Svenja Kaiser holds a BA in Media Studies and Literature and worked as an assistant in Media Design. She is a student in the masters programme Media Culture and a student assistant in the project "Media Practices and Copyright Law", conducted at the Collaborative Research Center "Media of Cooperation" (University of Siegen). 


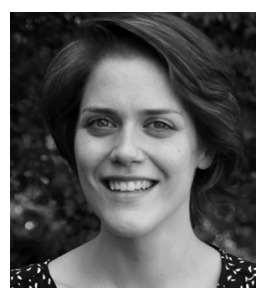

Vanessa Isenberg is a student in the masters programme Media Culture at the University of Siegen and a student assistant in the project "Media Practices and Copyright Law", conducted at the Collaborative Research Center "Media of Cooperation" (University of Siegen). Her bachelor thesis was a qualitative study of cooperative practices and work negotiations in the computer-demo scene.

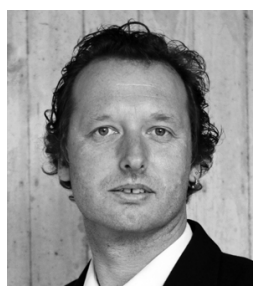

Jörg-Uwe Nieland studied Political Science, History, Philosophy and Sports Science at the Universities of Duisburg, Bochum and Berlin. In 2006, he received his PhD from the University of Duisburg-Essen. Since $\mathbf{2 0 0 9}$ he has been a senior researcher at the German Sport University Cologne and at the Institute for Political Science (University of Duisburg-Essen). Since 2016 he has been associated with the project "Media Practices and Copyright Law", conducted at the Collaborative Research Center "Media of Cooperation" (University of Siegen). 